\title{
Thermal and Hygric Expansion of High Performance Concrete
}

\author{
J. Toman, R. Černý
}

The linear thermal expansion coefficient of two types of high performance concrete was measured in the temperature range from $20{ }^{\circ} \mathrm{C}$ to $1000^{\circ} \mathrm{C}$, and the linear hygric expansion coefficient was determined in the moisture range from dry material to saturation water content. Comparative methods were applied for measurements of both coefficients. The experimental results show that both the effect of temperature on the values of linear thermal expansion coefficients and the effect of moisture on the values of linear hygric expansion coefficients are very significant and cannot be neglected in practical applications.

Keywords: concrete, linear thermal expansion, linear hygric expansion, moisture, temperature.

\section{Introduction}

Length changes of porous materials can be affected by changes of both temperature and moisture content [1]. Hygric expansion is often not taken into account in practical measurements and calculations, although a higher content of moisture, particularly in the liquid state, can lead to hygric stresses which are at least comparable with thermal stresses [2]. In this paper, we measure both the linear thermal expansion coefficient and the linear hygric expansion coefficient of two types of high performance concrete.

\section{Thermal and hygric expansion parameters}

The infinitesimal change of length due to change of temperature is defined by

$$
\mathrm{d} l_{T}=l_{0} \alpha_{T} \mathrm{~d} T,
$$

where $l_{0}$ is the length at the reference temperature $T_{0}$, and $\alpha_{T}$ is the linear thermal expansion coefficient. In an analogous way, the linear hygric expansion coefficient $\alpha_{u}$ can be defined

$$
\mathrm{d} l_{u}=l_{0} \alpha_{u} \mathrm{~d} u
$$

where

$$
u=100 \frac{m_{m}-m_{d}}{m_{d}}
$$

is the moisture content in $\%, m_{m}$ is the mass of the moistened material, $m_{d}$ the mass of the dried material.

Applying, in the first approximation, the superposition principle to the length changes due to temperature and moisture, we arrive at

$$
\mathrm{d} l=\mathrm{d} l_{\mathrm{T}}+\mathrm{d} l_{u}=l_{0}\left(\alpha_{T} \mathrm{~d} T+\alpha_{u} \mathrm{~d} u\right) .
$$

Defining the relative elongation as

$$
=\frac{\Delta l}{l}=\frac{1}{l_{0}} \int_{l_{1}}^{l_{2}} \mathrm{~d} l,
$$

we obtain

$$
\begin{gathered}
(u, T)={ }_{T}\left(u_{0}, T\right)+{ }_{u}\left(u, T_{0}\right)= \\
=\int_{T_{0}}^{T}\left(\frac{\partial}{\partial T}\right)_{u} \mathrm{~d} T+\int_{u_{0}}^{u}\left(\frac{\partial}{\partial u}\right)_{T} \mathrm{~d} u=\int_{T_{0}}^{T} \alpha_{T} \mathrm{~d} T+\int_{u_{0}}^{u} \alpha_{u} \mathrm{~d} u .
\end{gathered}
$$

\section{Experimental procedure}

In measuring the high-temperature linear thermal expansion coefficient, we employed an experimental device developed in our laboratory (see [3]). The device consists of cylindrical, vertically placed electric furnace with two bar samples located in the furnace. The first sample is the measured material, the second sample is a reference material with the known dependence of the thermal expansion coefficient on temperature. The length changes of the samples are measured mechanically outside the furnace by thin ceramic rods which pass through the furnace cover and are fixed on the top side of the measured sample. These ceramic rods pass by an indefinite temperature field, so that their elongation cannot be determined mathematically and a comparative method of determining the elongation of the rod is used.

In measuring the linear hygric expansion coefficient, we measured the length changes by the Carl Zeiss optical contact comparator with $\pm 1 \mu \mathrm{m}$ accuracy, and the mass changes were determined by the Sartorius electronic balance with $\pm 1 \mathrm{mg}$ accuracy. The basic set of points $l_{i}\left(m_{i}, T_{i}\right)$ necessary for determining the $\alpha(u)$ function was obtained in this way. The experiments were performed under isothermal conditions, with $T=(25.0 \pm 0.5)^{\circ} \mathrm{C}$.

First, the dependence of the relative elongation on moisture content was determined. The samples were first dried in a hot-air dryer at $T=110^{\circ} \mathrm{C}$, then moistened in the environment with a known relative humidity of $40 \%$, moistened to full water saturation, and dried first in natural way in the laboratory and finally in the hot-air dryer at $T=110^{\circ} \mathrm{C}$. Both length and mass changes were simultaneously measured during the moistening and drying processes.

\section{Materials and samples}

The experimental work was done with two types of high performance concrete used in nuclear power plants: Penly concrete and Temelin concrete.

Penly concrete was used for a concrete containment building in a nuclear power plant in France (samples were obtained from M. Dugat, Bouygues Company, France). It had a dry density of $2290 \mathrm{~kg} / \mathrm{m}^{3}$, and consisted of the following components: Cement CPA HP Le Havre $\left(290 \mathrm{kgm}^{-3}\right)$, sand 0/5 size fraction $\left(831 \mathrm{kgm}^{-3}\right)$, gravel sand $5 / 12.5$ size fraction $\left(287 \mathrm{kgm}^{-3}\right)$, gravel sand $12.5 / 25$ size fraction $\left(752 \mathrm{kgm}^{-3}\right)$, 
calcareous filler PIKETTY $\left(105 \mathrm{kgm}^{-3}\right)$, silica fume $\left(30 \mathrm{kgm}^{-3}\right)$, water $\left(131 \mathrm{kgm}^{-3}\right)$, retarder CHRYTARD 1.7 , super-plasticizer Resine GT 10.62. The maximum water saturation was $4 \% \mathrm{~kg} / \mathrm{kg}$.

The Temelin concrete used for the concrete containment building of the Temelin nuclear power plant in the Czech Republic had a dry density of $2200 \mathrm{~kg} / \mathrm{m}^{3}$ and maximum water saturation $7 \% \mathrm{~kg} / \mathrm{kg}$. The composition was as follows: Cement 42.5 R Mokrá (499 $\left.\mathrm{kgm}^{-3}\right)$, sand 0/4 size fraction $\left(705 \mathrm{kgm}^{-3}\right)$, gravel sand $8 / 16$ size fraction $\left(460 \mathrm{kgm}^{-3}\right)$, gravel sand $16 / 22$ size fraction $\left(527 \mathrm{kgm}^{-3}\right)$, water $\left(215 \mathrm{kgm}^{-3}\right)$, plasticizer $4.5 \mathrm{~lm}^{-3}$.

The measurements of both linear thermal expansion and linear hygric expansion were performed on 12 samples each. The dimensions of the samples were $40 \times 40 \times 120 \mathrm{~mm}$, and the centers of the $40 \times 40 \mathrm{~mm}$ faces were provided with contact seats for use with the contact comparator.

\section{Experimental results}

\subsection{Linear thermal expansion coefficient}

Figs. 1a, b show the measured linear thermal expansion coefficient of both types of high performance concrete in the

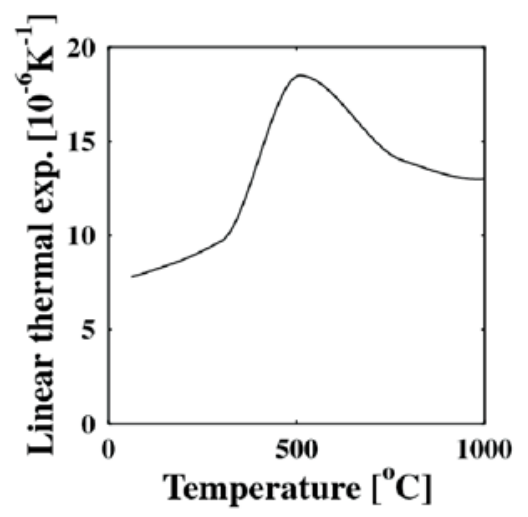

Fig. 1a: Dependence of the linear thermal expansion coefficient of Temelin concrete on temperature

temperature range from $20^{\circ} \mathrm{C}$ to $1000{ }^{\circ} \mathrm{C}$. The experimental results for Temelin concrete show an abrupt change in the character of the $\alpha(T)$ function at approximately $500{ }^{\circ} \mathrm{C}$. The course of the $\alpha(T)$ function for Penly concrete is even more dramatic, with several maxima and minima. This is

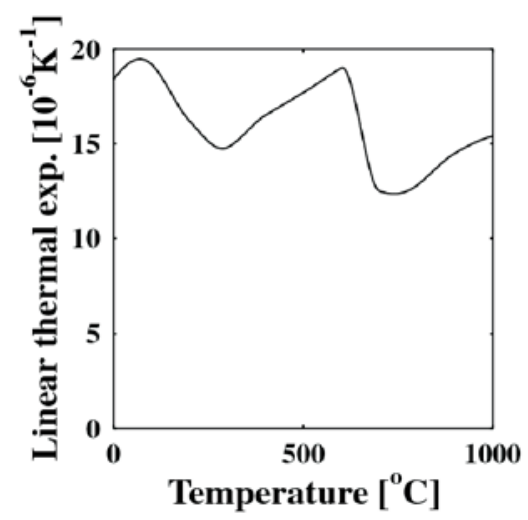

Fig. 1b: Dependence of the linear thermal expansion coefficient of Penly concrete on temperature apparently a consequence of structural changes in the concrete due to the chemical processes taking place in the studied temperature range.

\subsection{Linear hygric expansion coefficient}

The measured results are summarized in Figs. 2a, b. Both types of high performance concrete exhibited a very similar behavior, and their linear hygric expansion coefficient decreased with the moisture content.

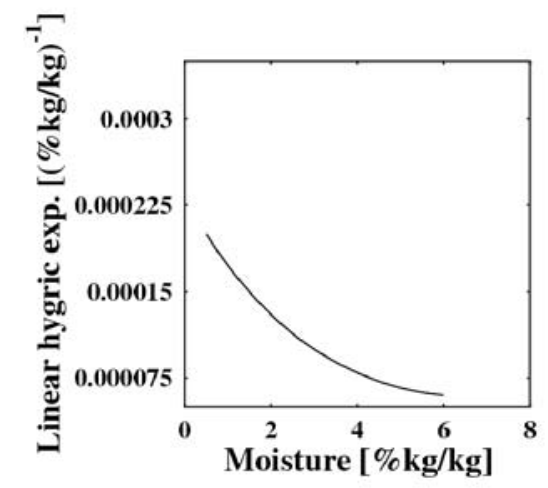

Fig. 2a: Dependence of the hygric expansion coefficient of Temelin concrete on temperature

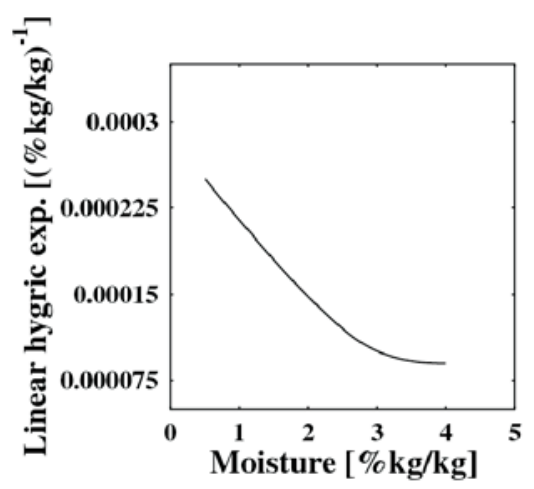

Fig. 2b: Dependence of the hygric expansion coefficient of Penly concrete on temperature

\section{Conclusions}

The linear thermal expansion of two types of high performance concrete was determined in a wide temperature range, and the linear hygric expansion coefficient in wide moisture range. The changes both of linear thermal expansion coefficient with temperature and of linear hygric expansion coefficient with moisture were found to be very significant, so that they cannot be neglected in practical applications.

\section{Acknowledgement}

This paper is based on work supported by the Ministry of Education of the Czech Republic, under contract No. CEZ: J04/98: 210000004. 


\section{References}

[1] Schulgasser, K.: Moisture and Thermal Expansion of Wood, Particle Board and Paper. Paper and Timber, No. 6, 3 (1988)

[2] Toman, J., Černý, R.: Coupled Thermal and Moisture Expansion of Porous Materials. Int. J. Thermophysics, Vol. 17, 271 (1996)

[3] Toman, J., Černý, R.: Measuring the Thermal Expansion of Building Materials at High Temperatures. Proceedings of the Seminar: Research Activities of Departments of Physics in Czech and Slovak Republic, p. 51, STU Bratislava, 1997 (in Czech)

Prof. Mgr. Jan Toman, DrSc.

Department of Physics

phone: +420224354694

e-mail:toman@fsv.cvut.cz

Prof. Ing. Robert Černý, DrSc.

Department of Structural Mechanics

phone: +420224354429

e-mail: cernyr@fsv.cvut.cz

CTU, Faculty of Civil Engineering

Thákurova 7, 16629 Prague 6

Czech Republic 